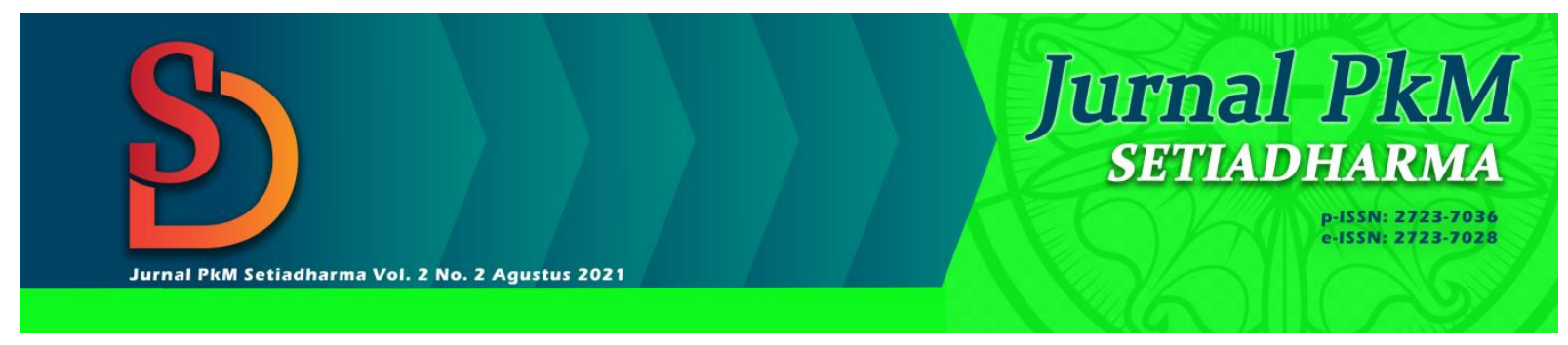

\title{
PELATIHAN PROGRAM PENDAMPINGAN PESERTA DIDIK DI SMA KRISTEN CITRA BANGSA KUPANG DALAM MELAKSANAKAN PENBELAJARAN JARAK JAUH (PJJ)
}

\author{
Junihot M. Simanjuntak, Agus Setio, Arnes Dela Lumban Toruan, Febri Yanti Zebua, \\ Simson Nullik \\ Sekolah Tinggi Teologi Kharisma Bandung \\ agussetio318@gmail.com,sihombingarnes@gmail.com
}

\section{Diterima: 03-07-2021 \\ Direview: 09-07-2021 31-07-2021 \\ Direvisi: 30-07-2021 17-08-2021 \\ Diterbitkan: 30-08-2021}

Keywords: training, program, mentoring, students, distance learning

Kata Kunci: pelatihan, program, pendampingan, peserta didik, Pembelajaran Jarak Jauh

\section{Abstract}

The objectives of this service are: 1) To review the role of teachers in the preparation of planning and implementation of distance learning so that it runs effectively in the field in accordance with the plans that have been prepared. 2) Provide distance learning that is of interest to students in accordance with programmed learning. The form of this activity is distance learning assistance for students of Citra Bangsa Christian High School Kupang. Participants in this activity consisted of: 1) Citra Bangsa Kupang Christian High School teachers, and 2) Class X, XI, and XII students. This activity is carried out by teaching methods using videos, lectures, discussions and questions and answers. As for this mentoring activity, 1) the Citra Kupang Christian High School teachers experienced an increase in the preparation of distance learning programs after being given training and mentoring; and 2) Citra Bangsa Kupang Christian High School teachers are skilled in implementing distance learning after being given assistance.

\section{Abstrak}

Tujuan dari pengabdian ini adalah: 1) Untuk meninjau peranan guru dalam penyusunan perencanaan dan pelaksanaan pembelajaran jarak jauh agar berjalan dengan efektif dilapangan sesuai dengan perencanaan yang sudah disusun. 2) Memberikan pembelajaran jarak jauh yang diminati oleh peserta didik sesuai dengan pembelajaran yang telah terprogram. Bentuk kegiatan ini adalah pendampingan pembelajaran jarak jauh peserta didik SMA Kristen Citra Bangsa Kupang. Peserta kegiatan ini terdiri dari: 1) Guru-guru SMA Kristen Citra Bangsa Kupang, dan 2) Peserta didik kelas X, XI, dan XII. Kegiatan ini dilakukan dengan metode mengajar menggunakan video, ceramah, diskusi dan tanya jawab. Adapun kegiatan pendampingan ini menghasilkan 1) guru-guru SMA Kristen Citra Kupang mengalami peningkatan dalam penyusunan program pembelajaran jarak jauh setelah diberikan pelatihan dan pendampingan; dan 2) guru- guru SMA Kristen Citra Bangsa Kupang terampil dalam mengimplementasikan pembelajaran jarak jauh setelah diberikan pendampingan. 


\section{PENDAHULUAN}

Pandemi Covid-19 telah melanda Indonesia sejak tahun 2020 dan memakan banyak korban jiwa. Sampai saat ini, bangsa Indonesia berupaya untuk memulihkan keadaan negara dari dampak pandemi ini. Salah satu yang terus diupayakan untuk meningkat dan mengembangkan kualitas dari masyarakat adalah pendidikan. Pandemi ini telah mengubah sistem pendidikan dari belajar tatap muka menjadi Pembelajaran Jarak Jauh (PJJ). Hal ini sesuai keputusan Menteri Pendidikan dan Kebudayaan Republik Indonesia Nomor 35952/MPK.A/HK/2020 yang mengemukakan tentang: "pembelajaran secara daring dan bekerja dari rumah dalam rangka pencegahan penyebaran covid-19."1

Kementerian Pendidikan dan Kebudayaan memberikan pernyataan pada tanggal 20 April 2021 setelah berjalannya satu tahun PJJ ini diterapkan bahwa ternyata ditemukan beberapa masalah yaitu: "Kesatu, anak didik tidak bisa menyerap pelajaran dengan baik karena belum terbiasa belajar secara dari melalui zoom. Kedua, faktor teknis yaitu bantuan kuota pulsa yang diberikan Kementerian Pendidikan dan Kebudayaan (KEMDIKBUD), belum dianggap maksimal dalam menutup permasalahan PJJ, sebab banyak anak di daerah terluar dan tertinggal tidak punya handphone dan sulit mengakses internet sehingga kuota pulsa ini menjadi sia-sia. Ketiga, hubungan batin antar peserta didik dan guru menjadi dingin karena tidak pernah bertatap muka dan saling menyapa selama satu tahun. Keempat, peserta didik juga mengalami putus sekolah. Salah satu kasusnya adalah pesesta didik SMA di NTB yang memutuskan menikah dini."2

Abdul Rozak Fahrudi juga mengungkapkan beberapa hambatan dalam melaksanakan PJJ seperti: "Belum meratanya jaringan internet, belum meratanya penguasaan IPTEKS oleh guru maupun peserta didik, mahalnya paket internet, belum siapnya melaksanakan pembelajaran jarak jauh, dan orang tua yang sulit mendampingi anaknya dalam pembelajaran jarak jauh."3 Senada dengan hal tersebut, Sarwa juga mengungkapkan ada beberapa masalah yang muncul berkaitan dengan PJJ, yaitu: "Kesatu, guru merasa kesulitan untuk membuat Rencana Pelaksanaan Pembelajaran (RPP) karena dituntut untuk kreatif dalam menggunakan teknologi. Kedua, pembelajaran jarak jauh tidak dapat dilaksanakan secara efektif karena tingkat perekonomian keluarga yang berbeda-beda. Ketiga, Guru merasa kesulitan untuk bekerja sama dengan orang tua siswa. Keempat, siswa kurang termotivasi dalam pembelajaran jarak jauh. Kelima, guru merasa kesulitan dalam memberikan penilaian karena tidak bisa memastikan bahwa para siswa mengerjakan tes atau ulangan secara jujur dan mandiri."4

PJJ ini juga dirasakan oleh SMA Kristen Citra Bangsa Kupang. Guru dan peserta didik masih mengalami kesulitan dalam PJJ ini karena harus menggunakan berbagai macam aplikasi dalam melaksanakan kegiatan belajar mengajar. Guru dan Peserta didik juga mengalami kendala dalam hal jaringan maupun kuota internet untuk mengikuti pembelajaran daring tersebut. sebab itu, PJJ ini dibutuhkan kreativitas dalam pembelajaran sehingga materi dapat tersampaikan dengan baik dan tentunya untuk mengatasi kendala-kendala yang terjadi dalam proses pembelajaran.

Berdasarkan hal tersebut, program studi strata satu Pendidikan Agama Kristen (PAK) Sekolah Tinggi Teologi Kharisma memberikan kontribusi untuk mendampingi guru berjumlah 39 orang dan peserta didik berjumlah 438 orang di SMA Kristen Citra Bangsa Kupang dalam pembelajaran jarak jauh. Hal ini bertujuan untuk tercapai tujuan belajar

\footnotetext{
${ }^{1}$ Kementerian Pendidikan dan Kebudayaan Republik Indonesia, "Surat Edaran Menteri Pendidikan Dan Kebudayaan Republik Indonesia Nomor 35952/MPK.A/HK/2020," Mendikbud RI (2020): 1-2.

${ }^{2}$ Pengelola Web Kemdikbud, "Dampak Negatif Satu Tahun PJJ: Dorongan Pembelajaran Tatap Muka Menguat," Kementrian Pendidikan Dan Kebudayaan.

${ }^{3}$ Abdul Rozak Fahrudin, "Permasalahan Dan Solusi Pembelajaran Jarak Jauh Di Masa Pandemi Covid-19," Samarinda Pos.

${ }^{4}$ Sarwa, Pembelajaran Jarak Jauh: Konsep, Masalah, Dan Solusi (Indramayu: Adab, 2021), 2-3.
} 
yang dialami oleh guru maupun peserta didik, seperti yang dijelaskan oleh Junihot Simanjuntak: "Tujuan belajar ialah agar peserta didik mengalami proses pembelajaran dan meresponi dengan tepat melalui pemilihan, penekanan materi pembelajaran dan aktivitas dalam mempersiapkan pelajaran dan pengajaran, di kelas maupun di lapangan oleh seorang guru." 5

\section{METODE PELAKSANAAN}

Metode pelaksanaan yang digunakan oleh penulis adalah pendekatan kualitatif deskriptif. Menurut Nana Syaodih: "Penelitian kualitatif menggunakan desain penelitian studi kasus dalam arti penelitian difokuskan pada suatu fenomena saja yang dipilih dan ingin dipahami secara mendalam, dengan mengabaikan fenomena lainnya."6 Penulis ingin memfokuskan penelitian untuk dipahami lebih dalam. Mengutip penjelasan Sukmadinata, Muh. Fitrah \& Luthfiyah menjelaskan, "Penelitian deskriptif adalah suatu metode penelitian yang ditujukan untuk menggambarkan fenomena yang ada, yang berlangsung saat ini atau saat yang lampau. Penelitian ini tidak mengadakan manipulasi atau pengubahan pada variabel-variabel bebas, tetapi menggambarkan suatu kondisi apa adanya."7

Berdasarkan hal tersebut, penulis melakukan pendekatan penelitian deskriptif untuk menggambarkan kondisi yang terjadi pada masalah yang ditemukan dan kemudian memfokuskan kepada masalah yang akan dibahas. Metode ini yang digunakan dalam penelitan di sekolah SMA Kristen Citra Bangsa Kupang.

\section{PEMBAHASAN DAN HASIL}

\section{Pembahasan}

Guru memiliki peran penting dalam membangun pendidikan di masyarakat, termasuk guru PAK. PAK diartikan sebagai upaya bersengaja dan sistematis, untuk mentransmisikan pengetahuan, nilai-niali, sikap-sikap, keterampilan-keterampilan dan tingkah laku yang konsisten dengan iman Kristen untuk mengupayakan perubahan dan pembaruan dan reformasi pribadi, kelompok bahkan struktur oleh kuasa Roh Kudus."8 Hal ini lah yang terus diupayakan oleh Guru PAK agar peserta didik hidup dalam nilainilai Kristen yang dikerjakan oleh kuasa Roh Kudus.

Dalam kegiatan Pembelajaran Jarak Jauh (PJJ) ini, guru PAK mengupayakan kegiatan pembelajaran yang diminati oleh peserta didik. Guru PAK meneladani Yesus: dengan berbagai metode dilakukan-Nya secara luar biasa dan mampu menarik perhatian khalayak ramai yang sudah bosan dengan cara mengajar guru-guru agama Yahudi. Lukas menuliskan bahwa Yesus menggunakan media yang sesuai konteks di mana Dia mengajar. Dia yang digunakann-Nya sangat familiar dengan pendengar saat itu. ${ }^{9}$ Metode mengajar Yesus sangat bervariasi, tergantung pada tujuan, bahan pengajaran dan situasi pendengar. Dalam mengajar, Yesus memakai metode ceramah, bimbingan, dialog, perjumpaan, simbolis maupun studi kasus. Semua metode itu dilakukan-Nya dengan

5Junihot Simanjuntak, Ilmu Belajar Dan Didaktika Pendidikan Kristen (Yogyakarta: Andi, 2017), 64.

${ }^{6}$ Nana Syaodih Sukmadinata, Metode Penelitian Pendidikan (Bandung: PT Remaja Rosdakarya, 2008), 99.

${ }^{7}$ Muh. Fitrah dan Luthfiyah, Metodologi Penelitian: Penelitian Kualitatif, Tindakan Kelas \& Studi Kasus (Sukabumi: Cv. Jejak, 2017), 36.

${ }^{8}$ B. Samuel Sidjabat, Strategi Pendidikan Kristen (Yogyakarta: Andi, 1994), 28.

${ }^{9}$ Donna Mutiara Nainggolan, Nehemia Nome, and Ridolf S.Th. Manggoa, "Pentingnya Kontekstualisasi Pada Pendidikan Kristen,” Phronesis: Jurnal Teologi dan Misi 4, no. 1 (2021): 40-52. 
penuh kuasa sehingga menimbulkan minat yang sungguh-sungguh bagi setia pendengarNya (Mrk. 1:22)."10

Yesus menggunakan berbagai metode dalam mengajar sehingga menarik hati dari setiap pendengar. Guru PAK juga demikan, harus terus mengembangkan kreativitas dalam situasi PJJ karena covid-19 ini. Hal ini akan menimbulkan minat bagi peserta didik untuk terus mengikuti pembelajaran seperti yang Yesus alami.

Kemahiran Guru PAK sangat dibutuhkan dalam memberikan ajaran yang benar kepada peserta didik. Hal ini bertujuan agar PAK tercapainya tujuan, yaitu: mengajar firman Tuhan, membawa kepada Kristus, dan memiliki keterampilan serta pembentukan spiritualitas." 11 Tujuan PAK adalah membawa peserta didik mengenal kehendak Allah sehingga dapat dipraktikkan dalam kehidupan peserta didik sehingga membawa perubahan yang signifikan. ${ }^{12}$

Tujuan yang lebih luas lagi adalah memimpin murid selangkah demi selangkah kepada pengenalan yang sempurna mengenai peristiwa-peristiwa yang terdapat dalam Alkitab dan pengajaran-pengajaran yang diberitakan olehnya, membimbing dan mempraktikkan setiap asas-asas darsar Alkitab. ${ }^{13}$ Guru PAK harus terus berupa mencapai tujuan PAK dalam PJJ yang berlangsung dalam masa pandemi covid-19.

Dalam mengemban tujuan PAK tersebut, langkah-langkah kegiatan yang dilakukan dalam Pelatihan Program Pendampingan Siswa di SMA Kristen Citra Bangsa Kupang dalam melaksanakan Pembelajaran Jarak Jauh (PJJ) dari tanggal 7 Januari 2021 dan berakhir pada tanggal 30 Maret 2021 adalah:

Kegiatan Pendahuluan. Hal-hal yang dilakukan yaitu: Kesatu, orientasi yaitu guru memimpin peserta didik untuk memusatkan perhatian kepada pembelajaran, melalui sebuah ilustrasi, membaca berita, menampilkan slide yang menarik, fenomena soal alam dan hal-hal yang menarik lainnya. ${ }^{14}$ Kedua, pemberian acuan yaitu menjelaskan materi pokok atau garis besar yang akan dipelajari. Ketiga, apersepsi yaitu peserta didik diberikan persepsi awal mengenai pembelajaran oleh guru. Keempat, motivasi yaitu guru memberitahukan manfaat dari pembelajaran yang berguna untuk sikap, keterampilan dan pengetahuan. ${ }^{15}$

Kegiatan Inti. Kegiatan yang dilakukan ini adalah menggunakan metode pembelajaran yaitu mengajar menggunakan video, ceramah, diskusi, dan tanya jawab. Kemudian menggunakan media pembelajaran yang tersedia seperti, zoom, google meet, dan google classroom. Menggunakan model-model pembelajaran yang disesuaikan dengan kondisi materi pembelajaran seperti ikuisi dan discovery learning.

Kegiatan Penutup. Hal-hal yang dilakukan adalah menemukan hasil pembelajaran yang bermanfaat untuk peserta didik maupun guru yang mengajar. Memberikan pertanyaan atau umpan balik untuk mengetahui hasil pembelajaran. Memberikan kegiatan berupa pemberian tugas kelompok atau individu kepada peserta didik dan memberikan informasi tentang pembelajaran di pertemuan selanjutnya. ${ }^{16}$

Tujuan Kegiatan. Tujuan dari kegiatan yang dilaksanakan di SMA Kristen Citra Bangsa Kupang oleh Mahasiswa Sekolah Tinggi Teologi Kharisma Bandung ini ialah untuk meninjau peranan guru dalam penyusunan perencanaan dan pelaksanaan pembelajaran

\footnotetext{
${ }^{10}$ John M. Nainggolan, Guru Agama Kristen Sebagai Panggilan Dan Profesi (Bandung: Bina Media Informasi, 2010), 15.

${ }^{11}$ John M. Nainggolan, Menjadi Guru Agama Kristen (Bandung: Generasi Info Media, 2007), 12.

${ }^{12}$ Nainggolan, Nome, and Manggoa, "Pentingnya Kontekstualisasi Pada Pendidikan Kristen."

${ }^{13}$ Homrighausen dan Enklaar, Pendidikan Agama Kristen (Jakarta: BPK Gunung Mulia, 2001).

${ }^{14}$ Wina Sanjaya, Strategi Pembelajaran Berorientasi Standar Proses Pendidikan (Jakarta: Kencana, 2008), 68.

${ }^{15}$ Agung Setyawanto, Rencana Pelaksanaan Pembelajaran (Jakarta: Kencana, 2012), 56.

${ }^{16}$ Wina Sanjaya, Perencanaan Dan Desain Sistem Pembelajaran (Jakarta: Kencana, 2010), 34.
} 
PELATIHAN PROGRAM PENDAMPINGAN PESERTA DIDIK ... (Junihot M. Simanjuntak, dkk)

jarak jauh agar berjalan dengan efektif di lapangan sesuai dengan perencanaan yang sudah disusun.

Manfaat Kegiatan. Manfaat dari kegiatan ini ialah memperkenalkan kepada masyarakat umum bahwa menjadi seorang pendidik khususnya di SMA Kristen Citra Bangsa bukanlah pendidik yang mengajar dengan sembarangan, tetapi ada kaidah dan tujuan yang sudah ditetapkan sebagai tujuan dari pembelajaran. Manfaat kegiatan ini bagi guru ialah agar guru bisa mengajar dengan disiplin sesuai dengan perencanaan yang sudah ditetapkan sehingga tidak keluar dari jalur perencanaan tersebut.

Khalayak sasaran kegiatan Pelatihan Program Pendampingan Siswa di SMA Kristen Citra Bangsa Kupang dalam melaksanakan PJJ adalah para guru sebagai tenaga pendidik yang melaksanakan proses berjalannya rencana pelaksanaan dan pembelajaran yang sudah dirancang:

\begin{tabular}{|l|l|l|l|}
\hline No & Program & $\begin{array}{l}\text { Deskripsi Pelaksanaan } \\
\text { Kegiatan }\end{array}$ & Indikator Pencapaian \\
\hline 1 & $\begin{array}{l}\text { Pendampingan } \\
\text { pembelajaran melalui } \\
\text { via zoom dan } \\
\text { pemberian tugas. }\end{array}$ & $\begin{array}{l}\text { kegiatan ini dilakukan } \\
\text { dengan mendampingi } \\
\text { peserta didik melalui via } \\
\text { zoom atau WA, serta } \\
\text { memadukan dengan } \\
\text { metode mengajar: } \\
\text { menonton video, } \\
\text { ceramah, diskusi dan } \\
\text { tanya jawab. }\end{array}$ & $\begin{array}{l}\text { Banyaknya kehadiran } \\
\text { peserta didik mengikuti } \\
\text { kegiatan pembelajaran PAK } \\
\text { melalui via zoom atau wa, } \\
\text { mampu mengerjakan tugas } \\
\text { yang diberikan, dan mampu } \\
\text { mengaplikasikan } \\
\text { pembelajaran PAK misalnya: } \\
\text { mampu berdoa, menyembah } \\
\text { Tuhan dan bersikap moral } \\
\text { yang baik. }\end{array}$ \\
\hline 2 & $\begin{array}{l}\text { Respons Guru, siswa- } \\
\text { siswi dan orangtua } \\
\text { (wali) terhadap } \\
\text { peserta didik dalam } \\
\text { kegiatan } \\
\text { pendampingan } \\
\text { pembelajaran PAK } \\
\text { melalui daring. }\end{array}$ & $\begin{array}{l}\text { Melakukan observasi } \\
\text { dan wawancara kepada } \\
\text { peserta didik, guru, } \\
\text { sekolah dan orangtua } \\
\text { terhadap pelaksanaan } \\
\text { pendampingan kegiatan } \\
\text { pembelajaran PAK } \\
\text { melalui via zoom atau } \\
\text { online. }\end{array}$ & $\begin{array}{l}\text { Sekolah, guru, pesertan didik } \\
\text { orangtua memberikan } \\
\text { respons yang baik kepada } \\
\text { peneliti. }\end{array}$ \\
\hline
\end{tabular}

\section{Hasil}

Pelatihan ini merupakan upaya meningkatkan kompetensi guru dalam mendampingi siswa belajar dengan metode PJJ. Terutama dalam melaksanakan pembelajaran jarak jauh ada berbagai masalah yang dialami oleh guru, terutama dalam menggunakan aplikasi yang biasa dipakai untuk pembelajaran jarak jauh misal zoom, google meet, google classroom, dan lain-lain.

Dalam hal ini ada yang perlu disiapkan oleh para guru adalah skill menggunakan aplikasi yang akan dipakai misal zoom, bagaimana cara menggunakan aplikasi zoom dan berbagai aplikasi lainnya dengan baik, itu diadakan pelatihan kepada guru-guru. Kegiatan pemberian pelatihan menggunakan aplikasi zoom akan disajikan di gambar 1.

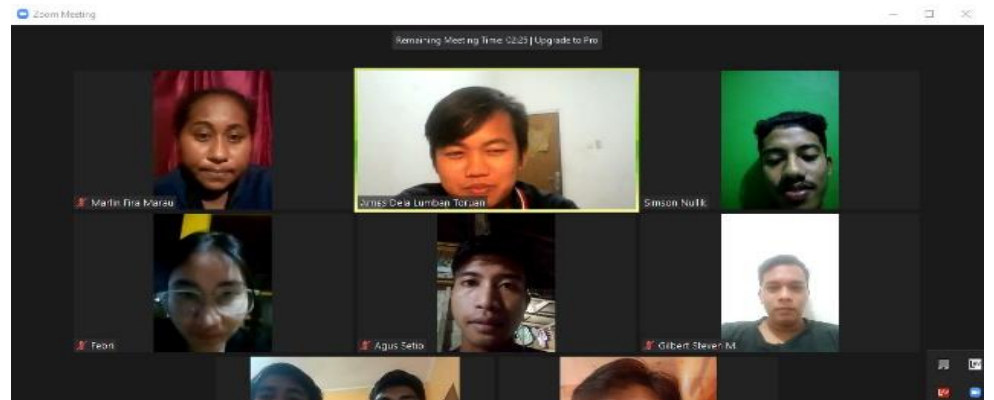


Tabel 2 rata-rata pemahaman program pelatihan pendampingan siswa dalam pembelajaran jarak jauh.

\begin{tabular}{|c|l|c|c|}
\hline No. & \multicolumn{1}{|c|}{ Pembahasan } & Presentase & Kategori \\
\hline $\mathbf{1}$ & $\begin{array}{l}\text { Pemahaman tentang program pelatihan } \\
\text { pendampingan siswa. }\end{array}$ & $70 \%$ & Baik \\
\hline $\mathbf{2}$ & $\begin{array}{l}\text { Keterampilan dalam menggunakan setiap } \\
\text { aplikasi yang digunakan. }\end{array}$ & $75 \%$ & Baik \\
\hline $\mathbf{3}$ & Kreativitas dalam mengembangkan bahan ajar. & $78 \%$ & Baik \\
\hline $\mathbf{4}$ & Kemampuan mencairkan suasana kelas. & $70 \%$ & Baik \\
\hline
\end{tabular}

Pelatihan program pendampingan pembelajaran jarak jauh ini juga dapat menggunakan google classroom, dengan ini juga dapat menjadi acuan sebagai pelengkap skill bagi seorang guru dalam menggunakan aplikasi untuk mengumpulkan tugas sehingga tidak tertumpuk karena banyaknya tugas lain, akan tetapi google classroom juga mempermudah guru untuk mengoreksi tugas yang sudah dikerjakan oleh setiap siswa. Kegiatan pemberian materi di google classroom akan disajikan dalam gambar 2.

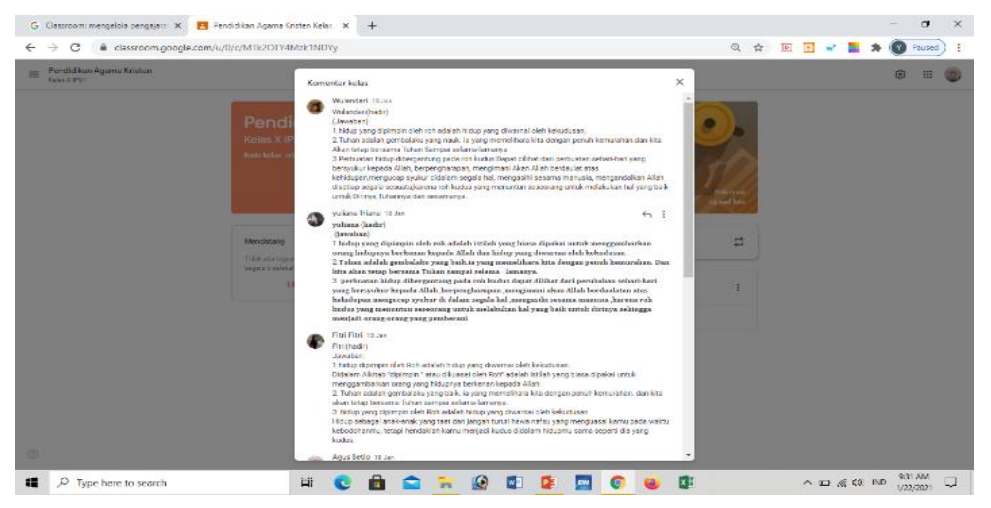

Kemudian, dalam kegiatan ini juga dapat menggunakan aplikasi lain yaitu google meet, aplikasi ini cukup mudah dan hampir sama seperti zoom namun bagi setiap siswa yang tidak mempunyai handphone dengan penyimpanan besar untuk aplikasi zoom terkadang tidak dapat terinstal, terkadang menjadi alasan kenapa siswa tidak ikut dalam kelas karena aplikasinya eror akibat tidak stabil dengan spesifikasi yang kurang memadai untuk menginstal aplikasi yang besar. Sehingga dalam hal ini dengan menggunakan google meet yang hanya bermodalkan alamat email tanpa harus instal aplikasinya dapat langsung ikut dalam kelas. Gambar 3 akan menyajikan bagaimana tampilan menggunakan google meet dalam menyampaikan materi.

Pelatihan program pendampingan ini dilakukan tiga kali $(3 \mathrm{x})$ dalam satu minggu pertemuan. Hal ini dibagi mulai dari kelas X, XI dan XII memiliki masing-masing satu kali pertemuan dalam 5 hari minggu efektif belajar dan diikuti oleh kelas X berjumlah 152 siswa, kelas XI berjumlah 161 siswa, dan kelas XII berjumlah 125 siswa yang aktif. 
PELATIHAN PROGRAM PENDAMPINGAN PESERTA DIDIK ... (Junihot M. Simanjuntak, dkk)

Hasil akhir daripada pelatihan program pendampingan peserta didik dalam melaksanakan pembelajaran jarak jauh dapat berjalan dengan baik. Dengan mengetahui apa saja aplikasi dan media yang dapat digunakan dan dikuasai dengan baik membuat guru juga dapat membuat variasi dalam mengajar sehingga tidak monoton dan membuat siswa bosan bahkan rasa jenuh juga dialami oleh guru itu sendiri karena terlalu kaku dalam mengajar.
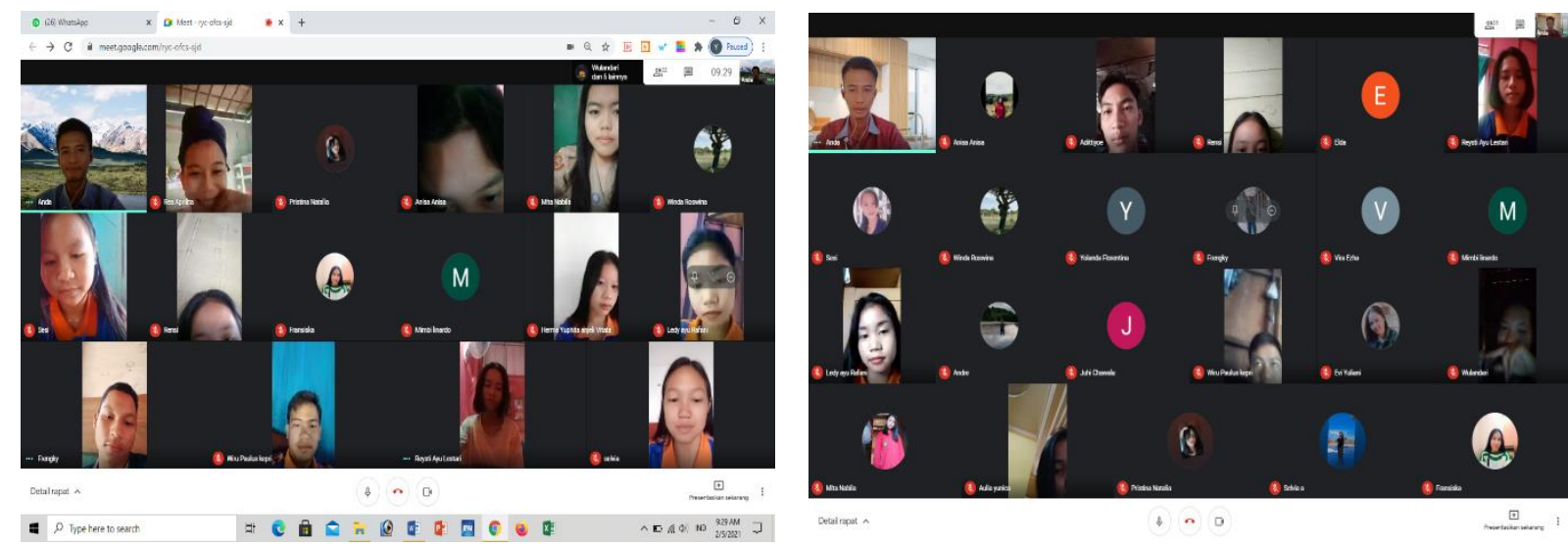

Tabel 3. Bagaimana pemahaman mengenai pelatihan program pendampingan siswa dalam melaksanakan pembelajaran jarak jauh usai melaksanakan pelatihan.

\begin{tabular}{|l|l|c|c|}
\hline No. & \multicolumn{1}{|c|}{ Uraian pembahasan } & Presentase & Kategori \\
\hline $\mathbf{1}$ & $\begin{array}{l}\text { Pemahaman program pendampingan peserta didik } \\
\text { dalam PJJ. }\end{array}$ & $80 \%$ & Baik \\
\hline $\mathbf{2}$ & $\begin{array}{l}\text { Skill dalam menggunakan aplikasi yang sudah bahas } \\
\text { dalam pelatihan. }\end{array}$ & $82 \%$ & Baik \\
\hline $\mathbf{3}$ & $\begin{array}{l}\text { Tingkat kesiapan dan kematangan dalam } \\
\text { menyampaikan materi dan menggunakan aplikasi. }\end{array}$ & $80 \%$ & Baik \\
\hline $\mathbf{4}$ & $\begin{array}{l}\text { Kreatif dalam menggunakan bahan dan alat seadanya } \\
\text { dalam mengajar. }\end{array}$ & $79 \%$ & Baik \\
\hline $\mathbf{5}$ & $\begin{array}{l}\text { Antusiasme peserta didik dalam mengikuti } \\
\text { pembelajaran. }\end{array}$ & $85 \%$ & Baik \\
\hline $\mathbf{6}$ & $\begin{array}{l}\text { Kemampuan dalam menyampaikan materi kepada } \\
\text { peserta didik sehingga tidak monoton. }\end{array}$ & & \\
\hline
\end{tabular}

\section{KESIMPULAN}

Pelatihan program pendampingan peserta didik di SMA Citra Bangsa Kupang dalam melaksanakan Pembelajaran Jarak Jauh (PJJ) berupaya semaksimal mungkin untuk giat mengajarkan kebenaran Firman Tuhan. Kegiatan ini tentunya untuk mendorong para guru berkembangan memanfaat kan teknologi dan mampu berkreasi agar peserta didik memiliki minat pembelajaran terhadap Pendidikan Agama Kristen (PAK). Pelatihan ini menjadi kontribusi kepada guru di SMA Citra Bangsa Kupang untuk terus berupaya agar tujuan PAK tercapai dalam diri pribadi peserta didik. guru memiliki kewajiban sebagai pengajar firman. Kewajiban itu membawanya pada tujuan yaitu menjadikan setiap orang menjadi murid Yesus yang merupakan Amanat Agung yang harus dijalankan setiap waktu (Mat. 28:19-20).

\section{DAFTAR PUSTAKA}


Homrighausen dan Enklaar. Pendidikan Agama Kristen. Jakarta: BPK Gunung Mulia, 2001.

Kementerian Pendidikan dan Kebudayaan Republik Indonesia. "Surat Edaran Menteri Pendidikan Dan Kebudayaan Republik Indonesia Nomor 35952/MPK.A/HK/2020." Mendikbud RI (2020): 1-2.

Muh. Fitrah dan Luthfiyah. Metodologi Penelitian: Penelitian Kualitatif, Tindakan Kelas \& Studi Kasus. Sukabumi: Cv. Jejak, 2017.

Nainggolan, Donna Mutiara, Nehemia Nome, and Ridolf S.Th. Manggoa. "Pentingnya Kontekstualisasi Pada Pendidikan Kristen." Phronesis: Jurnal Teologi dan Misi 4, no. 1 (2021): 40-52.

Nainggolan, John. M. Menjadi Guru Agama Kristen. Bandung: Generasi Info Media, 2007.

Nainggolan, John M. Guru Agama Kristen Sebagai Panggilan Dan Profesi. Bandung: Bina Media Informasi, 2010.

Pengelola Web Kemdikbud. "Dampak Negatif Satu Tahun PJJ: Dorongan Pembelajaran Tatap Muka Menguat.” Kementrian Pendidikan Dan Kebudayaan.

Rozak Fahrudin, Abdul. "Permasalahan Dan Solusi Pembelajaran Jarak Jauh Di Masa Pandemi Covid-19." Samarinda Pos.

Sanjaya, Wina. Perencanaan Dan Desain Sistem Pembelajaran. Jakarta: Kencana, 2010.

-_- Strategi Pembelajaran Berorientasi Standar Proses Pendidikan. Jakarta: Kencana, 2008.

Sarwa. Pembelajaran Jarak Jauh: Konsep, Masalah, Dan Solusi. Indramayu: Adab, 2021.

Setyawanto, Agung. Rencana Pelaksanaan Pembelajaran. Jakarta: Kencana, 2012.

Sidjabat, B. Samuel. Strategi Pendidikan Kristen. Yogyakarta: Andi, 1994.

Simanjuntak, Junihot. Ilmu Belajar Dan Didaktika Pendidikan Kristen. Yogyakarta: Andi, 2017.

Sukmadinata, Nana Syaodih. Metode Penelitian Pendidikan. Bandung: PT Remaja Rosdakarya, 2008. 